\title{
Commercial and anti-hunger sector views on local govemment strategies for helping to manage food waste
}

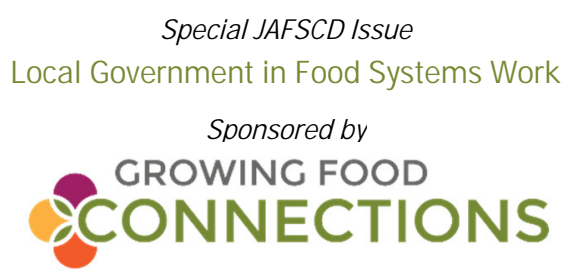

Jennifer J. O tten, ${ }^{a *}$ Sara D iedrich, ${ }^{b}$ Katherine G etts, ${ }^{\mathrm{c}}$ and Christine Benson ${ }^{\mathrm{d}}$

University of Washington

Submitted D ecember 3, 2017 / Revised January 25 and February 14, 2018 / Accepted February 14, 2018 /

Published online 0 ctober 17, 2018

Citation: Otten, J. J., D iedrich, S., Getts, K., \& Benson, C. (2018). Commercial and anti-hunger sector views on local government strategies for helping to manage food waste. Journal of A griculture, F ood Systems, and Community D evelopment, 8(Suppl. 2), 55- 72. https:/ / doi.org/ 10.5304/ jafscd.2018.08B.002

Copyright ( 2018 by the Authors. Published by the Lyson Center for Civic Agriculture and Food Systems. Open access under CC BY license.

\begin{abstract}
In the United States, $40 \%$ of all food intended for human consumption is lost or wasted. This has economic, environmental, and social consequences and equity concerns that justify the involvement of local governments. In addition, local governments

a * C orresponding author: Jennifer J. Otten, $\mathrm{PhD}, \mathrm{RD}$, Nutritional Sciences Program, Center for Public Health Nutrition, D epartment of Environmental and O ccupational Health Sciences, School of Public Health, University of Washington; 306c Raitt Hall; Seattle, WA 98105 USA; +1-206-221-8233; jotten@uw.edu

b Sara Diedrich, MPH, RD, research coordinator, Center for Public Health Nutrition, University of Washington.

Ms. D iedrich is now at Share O ur Strength's Cooking Matters Colorado; 1824 Lincoln Street, D enver, CO 80203 USA; sdiedrich@ strength.org

${ }^{c}$ Katherine G etts, MPH, RD, Center for Public Health Nutrition, School of Public Health, University of Washington, 330 Raitt Hall; Seattle, WA 98105 USA; kgetts@uw.edu

d Christine Benson, MPH, RD, graduate research assistant, Center for Public Health Nutrition, University of Washington. Ms. Benson is now at the Healthy Eating Active Living Program, Washington State D epartment of Health; Olympia, WA USA; chris.benson@doh.wa.gov
\end{abstract}

are well positioned to support the systems-level innovations and systems- and equity-oriented approaches necessary for bringing together various sectors to tackle food waste issues. However, little is known about how food-generating businesses and anti-hunger agencies think local governments and public agencies could work with them to address food waste through source reduction (i.e.,

\section{Statement on Previous Reporting of Data}

These findings have been previously published, in part, in a report to the City of Seattle:

Otten, J., Diedrich, S., Getts, K., \& Benson, C. (2016). Food waste prevention and recovery assessment report for Seattle Public U tilities and the City of Seattle's 0 ffice of Sustainability and E nvironment. University of Washington Center for Public Health Nutrition. Retrieved from https:/ / depts.washington. edu/ uwcphn/ reports/ SeattleFoodWasteReport.PDF

\section{Funding Disclosure}

This work was supported by a contract (Agreement No. O SE 14-42) from the City of Seattle O ffice of Sustainability \& Environment, a University of Washington Top Scholar award to Ms. Benson, and University of Washington start-up funds awarded to D r. Otten. The content is solely the responsibility of the authors and does not represent the official views of the City of Seattle or Seattle Public Utilities. 
prevention) and feeding hungry people. These are the top two methods for waste reduction as outlined in U.S. Environmental Protection Agency (EPA)'s Food Recovery Hierarchy. Using qualitative interviews, this study presents the key challenges and facilitators of multiple Seattle-based anti-hunger agencies $(\mathrm{n}=8)$ and food-generating businesses $(\mathrm{n}=12)$ to addressing food waste prevention, recovery, and composting. This study also addresses how anti-hunger agencies and foodgenerating businesses interrelate within and between the two sectors. Interviewees also provided sector views on the potential roles of local government in this space. Strategies recommended for local governments included:

(1) committing resources that enable a systems approach. This can be accomplished by dedicating a staff or office to food waste issues, designating funding that is specific to food waste, incorporating equity and inclusivity, and serving as a convener of stakeholders;

(2) helping to standardize metrics and normalize waste audits. These practices are essential for understanding and scaling work within and between sectors, for measuring progress toward goals or fluctuations in the system, and for identifying priorities; and

(3) supporting the optimal operation of the emergency food system by helping improve infrastructure and efficiency.

\section{Keywords}

Food Waste, Food Recovery, Food Composting, Source Reduction, Food Waste Prevention, Food Waste Diversion, Food Waste Policy, Local Governments, Anti-Hunger, Q ualitative

\section{Introduction and Background}

In the United States, it is estimated that 30 to $40 \%$ of food intended for human consumption goes uneaten (Buzby, Wells, \& Hyman, 2014; Hall, Guo, Dore, \& Chow, 2009). This has economic (e.g., wasted money and labor), environmental (e.g., increased greenhouse gas emissions, wasted natural resources), social (e.g., missed opportunities to feed food insecure people), and equity (e.g., inequitable distribution of and access to recovered food) impacts that are predicted to worsen as the population increases in size (G unders, 2012; NRD C, 2017). At the local government level, staff are exploring what roles they can play to reduce these negative consequences. In 2015, the City of Seattle and Seattle Public Utilities (hereafter, "the City") worked with a research team at the University of Washington's Center for Public Health Nutrition (UW CPHN) to explore challenges and opportunities for food waste prevention and recovery among food-generating businesses and anti-hunger organizations. The purpose of this research was to inform the City of how they might foster food waste efforts and goals in this part of the food system ( $O$ tten, D iedrich, $G$ etts, \& Benson, 2016).

The E conomic, E nvironmental, and

Social Impacts of W asted F ood

It is estimated that Americans spend US\$166-218 billion each year growing, harvesting, processing, distributing, and disposing of food that is never eaten (Buzby \& Hyman, 2012; ReFED , 2016). This equates to a loss of 1,250 calories per day per person and costs each household an average of US $\$ 1,800$ per year (Buzby \& Hyman, 2012; NRD C, 2017; ReFED , 2016). While most food waste is likely inedible by the time it reaches the garbage, food is the number one contributor to landfills, with $95 \%$ of food waste ending up in the garbage rather than compost, producing negative impacts on the environment. (U.S. EPA, 2015c). In landfills, the decomposition of food produces methane, a greenhouse gas 25 times more harmful to the climate than carbon dioxide (U.S. EPA, 2015b). Uneaten food also represents wasted land, soil, nutrients, water, energy, labor, and missed opportunities to feed hungry people (NRD C, 2017). By food type, seafood has the highest rate of waste, followed by fresh produce. The Washington State D epartment of Ecology estimates that 8\% of wasted food is edible at the time of disposal (NRD C, 2017; State of Washington, 2018).

Currently, 13\% of U.S. households are foodinsecure, and the Emergency Food Assistance Program spends nearly US\$700 million annually to provide food to low-income people (Coleman- 
Jensen, Rabbitt, G regory, \& Singh, 2016; USDA, 2016). It is projected that recovering one-third of uneaten food would be enough to feed all 42 million Americans considered food-insecure, although distribution would need to be considered in terms of equitable access (NRDC, 2017). These problems will be exacerbated by predicted population growth and increased food demand, assuming current waste levels (NRD C, 2017). However, national efforts to reduce food waste, such as those in the United Kingdom (UK), have been successful. Between 2007 and 2012, the UK population grew 4.5\%; yet total food demand stayed constant and food waste declined by 1.4 million tons--a $17.5 \%$ reduction (Q uestad \& Murphy, 2014). A 2017 study of nearly 1,200 companies across 17 countries showed that businesses implementing food waste reduction efforts had an average 14 -fold financial return on investment (Hanson \& Mitchell, 2017). These and other successes have instigated

Figure 1. U.S. Environmental Protection Agency Food Recovery Hierarchy

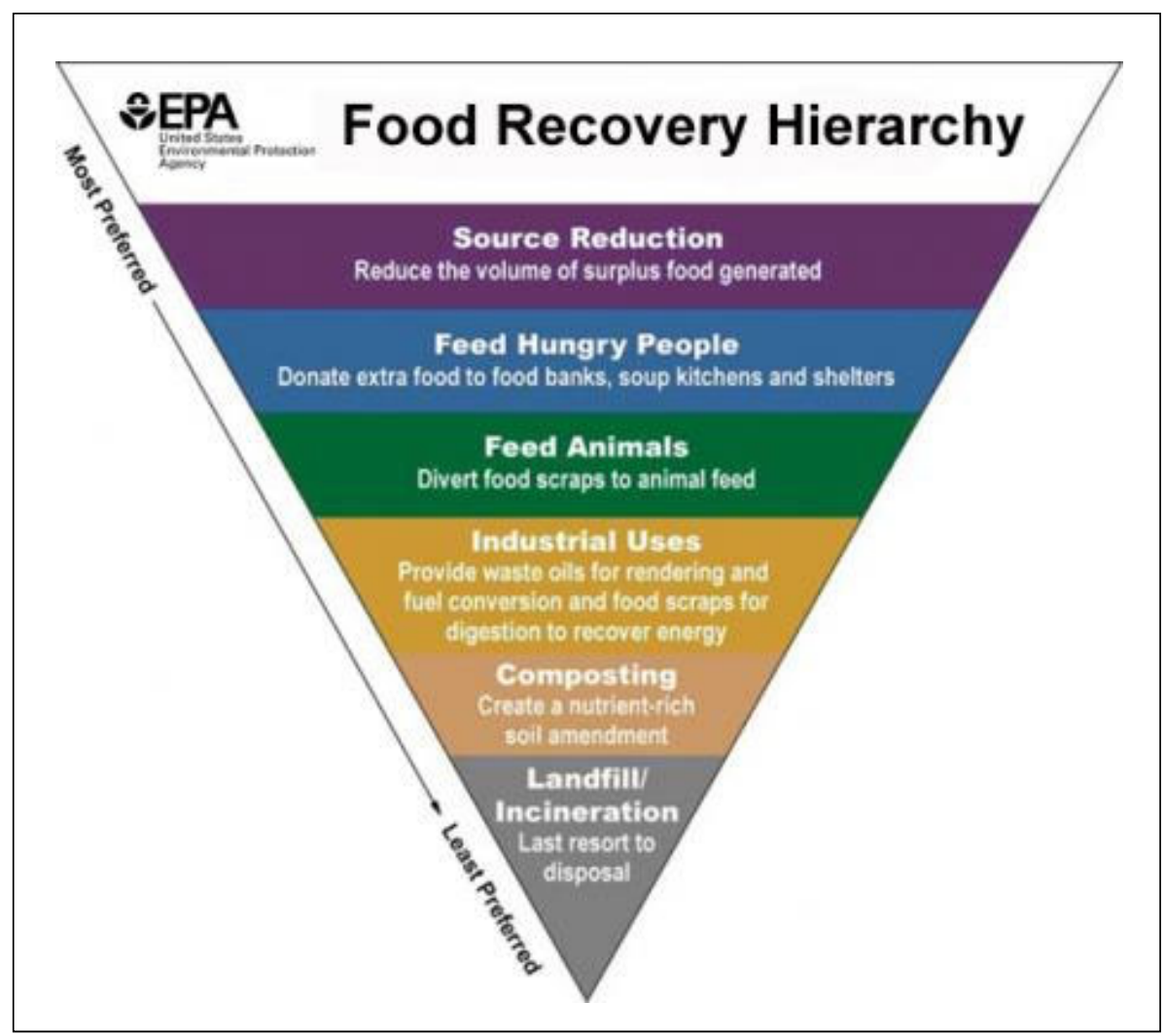

Source: https:// www.epa.gov/ sustainable-management-food/ food-recovery-hierarchy governmental interest in and efforts to tackle the problem of food waste.

G overnmental E fforts at F ood W aste Prevention and Recovery

In 2015, the U.S. Environmental Protection Agency (EPA) and U.S. D epartment of Agriculture set national targets to cut food waste $50 \%$ by 2030 (NRD C, 2017). That same year, the EPA released its Food Recovery Hierarchy, which ranks recovery efforts from the most to least preferred methods (U.S. EPA, 2015a). The hierarchy named source reduction as the highest priority, followed by food recovery, feeding animals, repurposing for industrial uses, composting, and landfilling. See Figure 1 for the EPA Food Recovery Hierarchy.

In tandem, food waste related legislation has increased and includes a number of federal bills on food recovery and date labeling that have been introduced in Congress, several state-level composting bills, and a few state-level tax incentives for food donations (NRD C, 2017). States and local public agencies have also increasingly begun to develop and incubate systems, environment, and education programs and activities focused on food waste (Benson, Daniell \& O tten, 2017). However, little is known about the capacity for and the ways in which stakeholders work together within local systems and with public agencies on food waste prevention and diversion. In 2016, the City of Seattle sought to assess the work done to date by food-generating businesses and antihunger agencies to better understand the successes and challenges of the current system. 
Food W aste E fforts by the City of Seattle Since the late 1990s, Seattle Public Utilities (SPU) has been involved in commercial food waste prevention and recovery efforts via infrastructure and research grants. These efforts have included purchasing refrigerated trucks and equipment for food preparation and storage, linking anti-hunger agencies and food generating businesses, providing education about food liability, handling, and safety laws, piloting food waste prevention protocols, funding technology, and starting compost collection projects (Musick, 2010; SPU, 2012; 2014). These infrastructure grants were projected to divert 23,000 tons of edible food from waste streams for 2010-2020. In one research pilot, SPU shared with two large-scale commercial food operations the cost of working with LeanPath, a company that helps food-service businesses reduce food waste through a computerized tracking system that provides frequent feedback to employees and managers. O ver a period of approximately 14 months, the university and hospital reduced food waste by $18 \%$ and $31 \%$ respectively (Emsdorff, 2009). In another project, SPU worked with 17 food banks to start compost collection programs and, in the first two years, diverted an estimated 540 tons of surplus food from the landfill. At the same time, the City of Seattle, through its Food Action Plan and Climate Action Plan, has highlighted the prevention, recovery, and composting of food waste as several of its top goals (City of Seattle, 2012; 2013). With the support of these action plans, in 2015 the City passed and enforced a law that prohibited residences and businesses from placing compostable food and compostable food packaging in the garbage (City of Seattle, 2015).

The C urrent Study

The above efforts are examples of investments made by governments and national agencies to engage in food waste prevention and diversion. Despite the efforts of SPU, a 2012 SPU study found that food and compostable food packaging still constitute about $30 \%$ of commercial waste; in particular, $53 \%$ of restaurant waste by weight was food, and $9 \%$ of waste by weight was compostable or food-soiled items (SPU, 2012). In addition, in a
2014 progress report of the anti-hunger sector, SPU found that anti-hunger agencies reported increased demand for food, a need for more donations, and aging equipment (SPU, 2014). Thus, City partners were interested in advancing their efforts more systematically by engaging stakeholders across multiple sectors. To achieve this, they asked the UW Center for Public Health Nutrition to interview participants from the anti-hunger and commercial sectors using a more systemoriented perspective, and to interview other public agencies to find out what they were doing on this topic. The analysis of public agency interviews is published elsewhere (Benson et al., 2017). The purpose of this analysis is to present the findings and recommendations from interviews with multiple anti-hunger agencies and food-generating businesses about (1) their food waste prevention and recovery strategies, their barriers and facilitators to food waste prevention and recovery, and to gain a better understanding of how prevention and recovery strategies interrelate, and (2) their views on the potential role of local government in this space.

\section{Methods}

This study used semistructured qualitative interviews with participants from 20 anti-hunger agencies and food-generating businesses. The University of Washington Institutional Review Board approved the study.

Participants and Procedure

From April through October 2015, the UW CPHN contacted potential interviewees via phone or email with a study invitation and description. The study sample was generated with the help of two public agency employees at the City of Seattle with knowledge pertaining to food waste. The anti-hunger agencies identified were Seattle-based or national organizations with a Seattle chapter (i.e., food banks, meal program providers, and anti-hunger distributors) and the food-generating businesses identified were Seattle-based or national chains with Seattle-based locations (i.e., grocery stores, restaurants, and large institutions, such as hospitals and universities). The anti-hunger agencies were selected based on achieving diversity in size, geographic area of the City, and clientele (e.g., age 
ranges, racial and ethnic backgrounds, and type, such as serving a primarily HIV/ AID S population).

\section{Semistructured Interviews}

The research team constructed two semistructured interview guides (i.e., one for anti-hunger agencies and one for food-generating businesses) (Brinkmann, 2013). Each guide contained a series of 23 to 25 open-ended questions to investigate each sector's challenges and successes pertaining to food waste prevention and recovery and to explore the ways in which public agencies could assist these organizations in improving prevention and recovery efforts. The interview guides were refined based on peer review by city agency collaborators and by the Seattle Public Utilities' Survey Review Panel. The anti-hunger interview guide focused on topics such as program scale, characteristics of current donors and donations, facilitators and barriers to food recovery and distribution, areas for improvement, and public agency roles. The foodgenerating business interview guide focused on topics such as characteristics of food donation and waste (e.g., amount, cause, types, pathways, targets); food waste prevention and donation strategies and challenges; areas for improvement; and public agency roles.

\section{D ata A nalysis}

Using best practices in qualitative analysis, interviews were analyzed using a refined codebook and D edoose software (D edoose, 2016; G uest \& MacQueen, 2008; MacQueen, McLellan, Kay, \& Milstein, 1998; Miles, Huberman \& Saldana, 2014). The research team discussed the preliminary findings to understand how they were related and their broader significance within the data. They also worked with City partners to develop recommendations to inform City activities. Key findings are described in the results section below and presented with illustrative quotes.

\section{Results}

Eight anti-hunger agencies and twelve foodgenerating businesses participated in the interviews. The anti-hunger agencies (i.e., food banks, meal and/ or grocery delivery organizations, a hunger relief agency, a food distributor, and a coalition of food programs) varied in size, geographic location, and clientele (e.g., clients were of varying ages and racial/ ethnic backgrounds). The businesses included five grocery stores (i.e., one organic store and co-op, one large national chain, one small local chain, one discount grocery store, and one wholesale grocer) and seven institutions or restaurants (i.e., one chef-owned fine-dining restaurant, one casual sit-down restaurant chain, one hospitalbased cafeteria, one large catering service, two large food service operations designed to serve employees or college students, and one prepared food wholesale distributor). Both sectors had locations in the City of Seattle or its metropolitan area.

This section summarizes major findings. In the first two sections, we use interviewees' qualitative descriptions to briefly describe how the antihunger and commercial sectors generate and recover wasted food. Next, we illustrate the lack of standardized metrics and goals within and between anti-hunger organizations and food-generating businesses. Without standardized metrics, there is no clear picture as to how much wasted food is generated and recovered by these sectors. Then, we provide each sector's challenges and facilitators to food waste prevention, food recovery, and composting - three of the EPA Food Waste Recovery Hierarchy categories from most to least preferred (U.S. EPA, 2015a). Finally, we present each sector's suggestions for public agency roles in the system.

F ood W aste $G$ eneration: Key System C haracteristics $\mathrm{G}$ enerally, anti-hunger agencies receive edible food donations and try to use as much as possible to serve their clients. Food waste is most commonly generated either when they receive expired food, near-expired food, or a greater volume of food than they are able to use. Interviewees universally reported diverting this to compost or garbage.

$\mathrm{G}$ rocery stores generate excess food for many reasons. Cosmetic imperfections such as bruises on produce, expiration, and food spoilage were the most commonly cited reasons for grocery store food waste. O ther reasons were food recalls, buyer pulls, damaged goods due to dropped items or ripped bags, and food returns from customers, the 
latter of which prevents re-use of food for human consumption. The majority of grocery store interviewees said they preferred to donate lightly bruised or nearly expired produce to food banks, but will also give lower quality food to farmers for animal feed or compost if inedible. Several interviewees mentioned using the EPA Food Recovery Hierarchy in making their diversion decisions. O ne interviewee described, "In order of choice, our preference is it goes to the food banks first... There are some farmers that pick up some feed stock of lettuce trimmings and that kind of thing at each of the stores and then feed them to the pigs and chickens. And then after that it goes into compost. None of it should be going into landfill."

Restaurants and institutions generally divide their food waste into pre-consumer and postconsumer food waste. Pre-consumer food waste is typically generated due to over-production, food trimmings, and spoilage. Many restaurants and institutions prepare and serve more food than customers will eat due to the unpredictability of food service (e.g., the inability to predict exact customer counts or consumer eating preferences at a catered event) and the potential for profit losses if they run out of food. For example, one restaurant interviewee said, "We're always going to slightly overstock. It's part of the strategy because the minute your shelf runs out of food, that's lost opportunity in sales." Many interviewees indicated that overproduction is particularly problematic in the catering component of their business; this is often due to lower than expected event turnouts. In addition, these businesses state that trim waste is inevitable, even when their staff are trained in techniques to reduce trim. Food spoilage due to poor inventory management, while rare, was another reason for food waste. All restaurants and institutions interviewed said they donate their preconsumer edible food waste (such as excess meals prepared) and compost their inedible food waste. One interviewee that sold packaged, prepared foods to retail outlets bought back their unsold food and donated it or sold it at a discount to outlet stores.

Post-consumer food waste generated by restaurants and institutions was food left on customer plates or customer-exposed caterer trays.
Patrons are often served large portions or take more food than they can eat (e.g., at catered events or buffets). Ideally, patrons or employees dispose of this food waste in the compost bin, but many interviewees said consumers and employees incorrectly sort food waste into the garbage.

F ood W aste Recovery: Key System Characteristics While the majority of grocery stores interviewed set up their donation programs independently, most restaurants and institutions use connector organizations, such as Food Lifeline or Food D onation Connection, to help them set up their donation system. G rocery store interviewees said they set up their donation program by calling the local food bank or visiting them in person and that they preferred to work with local entities to ensure they were supporting their community. O ne interviewee explained this, "I went over and asked to talk to the director. We made introductions and did a follow-up meeting to brainstorm." Restaurant and institution interviewees used Food Lifeline or another larger organization to help them set up their donation programs. These connector organizations also helped to provide them with pans, bags, and tags to make food donation easier. O ne interviewee described this process, "We don't donate directly to Food Lifeline. Food Lifeline puts us in touch with the organizations that can use it, and we donate directly to those organizations." Another interviewee described the process with a different organization, "Y es, we work through a national company called the Food D onation Connection. They connect us with local [anti-hunger organizations]. Y es, and then those partners come to our restaurants one to three times a weekideally, three times a week - and pick up any excess food."

\section{$M$ etrics and $\mathrm{G}$ oals}

Standardized metrics allow local governments to describe the current food waste situation, track progress, and garner support for programs (Benson et al., 2017). Although almost all interviewees involved in food donations reported measuring food wasted and/ or donations to some degree, there was a lack of standardized metrics within and between the two sectors. 
In terms of food waste, anti-hunger agencies typically did not report composting metrics or amounts but mentioned in the interview that they put large volumes of expired food in the compost. One mentioned that garbage and compost removal of expired foods cost them thousands of dollars a month. Food-generating businesses varied in the ways they reported food waste, often listing pounds, tons, or dollar amounts. Some businesses tracked the food waste they generated before and after it reached the consumer, while others only tracked one of these metrics. Businesses generally reported that it was challenging to track food waste that went into the compost, but a few tracked the number of used compost containers, whether full or not, that were used; this was because the composting collection company that many of them used reported their usage in this way. No businesses tracked the amount of food waste that went into the garbage.

Anti-hunger agencies varied in how they reported the food donations they received and the number of clients they served. For example, antihunger agencies reported food donations in pounds or tons over varying time periods, such as a month or year, or converted donated amounts into a monetary value, which also varied in the scale presented, such as by pound or meal. Similarly, anti-hunger agencies often reported the number of clients served over a period, such as an hour or a year, or they would report the number of meals served or pounds of food and/ or food bags provided.

Despite all food-generating businesses in this sample engaging in food donations to at least one anti-hunger agency, only five reported that they tracked the food they donated. The tracking systems varied and interviewees reported donations in pounds of food, in percent of food donated, and in receipts from the food bank. O ne business mentioned using their own inventory system to loosely track the donations, but explained that not all unsold, unused inventory was donated. See Figure 2 for quotes illustrating the wide variation in metrics for both sectors.

None of the anti-hunger agencies interviewed set goals or targets around food waste reduction. However, one agency implemented a logistics improvement program to get more clients in the door and, thus, more food out the door. With the help of a specialist, they made small changes such as rearranging their storage and pick-up areas to decrease wait time for clients and increased the number of clients from 50-60 to 120-140 over an hour.

Three businesses reported the presence of official food waste prevention targets and three businesses reported being in the process of creating targets. Targets varied in outcome, such as the volume of food or amount of individual food ingredient, and by the level of responsibility, such as by department or food prep station. Most businesses mentioned that these targets were set or being set at the corporate level. Two businesses without targets reported that they felt they did not need targets or that there was no corporate support for setting such goals. As one interviewee without a target stated, "At this time, no. If you're doing cook to flow, if you're producing the order, if you're not doing a lot of waste, then you will make your targets basically. I mean, that's just a standard business practice as opposed to being specific to waste."

\section{F ood W aste Prevention: Challenges and F acilitators}

\section{Challenges}

Consumer perceptions and expectations contribute to food waste by grocery stores. All five grocery store interviewees said that dealing with consumer expectations around perfect produce stocked in abundance motivated them to cull edible produce. As a result, almost none of the grocery stores sold blemished, bruised, or slightly damaged goods, even at a discount, except one discount store. Related, consumers are often unwilling to buy the last product on the shelf, thus grocers feel they must overstock. An interviewee explained, "Well, I think that everybody probably does that trick where they put stuff underneath the apples so that it looks bigger than it is. But then there is a problem with only putting a few of an item out therepeople won't buy it if there are only a few left. We tend to go for the abundance and we find that we move more product by actually putting out an abundant display." Interviewees from grocery 
Figure 2. Sectors Varied in How They Reported Food Recovery Metrics and Goals

Businesses varied in the ways they reported food waste, often listing pounds, tons, or dollar amounts:

- "We average between 300-800 lbs. of food scraps [across all our stores.]"

- "We basically use two metrics. One is food waste over the amount that we spend on food. We're also looking at food waste over seated headcount."

- "It's $5 \%$ at the most in terms of fresh food that could be wasted. It's a very small percentage of our total purchases."

- "We track everything in retail dollars and not tonnage, so let's say I do 7,000 dollars-worth"

- "A total of 187 tons [of food waste] a month for all the stores."

- "We in Seattle compost the kitchen prep scraps, which is about 300 gallons per week per restaurant."

- "We have a waste management portal that we put our waste in every day... it's going to be production waste...everything that's leftover from the end of the events, and then any dry storage or storage waste for that day."

- "We have the recycling department that keeps track of all the compost and garbage. They don't sort the garbage, and so the food waste that goes into there we don't keep track of. Again, that should be very minimal. The compost we do about 225 per month on average. But I think it's notable to say that that also includes paper products, compostable containers, and that kind of stuff. Not just food."

Anti-hunger agencies reported donated food in pounds or tons over different periods of time. Others used dollars or meal conversions to report their donations:

- "900,000 pounds of food that was recovered or donated"

- "775,000 pounds per year"

- "We expect to distribute 32 million pounds of food this year. Of the 32 million, $70 \%$ is donated."

- "We're procuring about 40,000 pounds a month."

- "Last year we brought in about 17.3 million pounds."

- "I think last year it was 212 tons"

- "Last year we estimated that we used US\$1.9M worth of rescued food in the organization."

- "We assign a monetary value to it. That changes from year to year. We assign that value based on the Feeding America's evaluation, which currently is US $\$ 1.72$ I think per pound."

- "We use a meal conversion."

- "We conservatively estimate at US $\$ 2.99$ a pound."

- "We are required to report that poundage in a variety of different categories, and so that would be meat, dairy, fresh fruits and vegetables, bread, and then dry goods, dry canned goods."

Anti-hunger agencies reported the scale they served in terms of people per hour or over a period of time. Others used bags, pounds, or meals to report their scale:

- "120-140 people through in an hour"

- "18,000-19,000 people a month just last year"

- "We range from serving a couple hundred families a month to thousands"

- "Between 1,000-1,100 families a week"

- "5,600 this past year"

- "We do 40,000 grocery bags a year and we do 162,000 meals"

- "We serve approximately 500,000 meals a year"

- "We put together 1,800 meals a day"

Businesses reported food donations in a variety of ways:

- "We are tracking the number of pounds of food that is being donated from the stores, as well as in getting help from the food bank to be able to identify how many families that helps based on that need."

- "For the food bank, $30 \%$ of our food is donated."

- "I get receipts for donations every time I donate. They should be sending them. I have kind of a thing of what they're tracking, because their tracking seems to be different from what we're tracking."

- "No, that's hard to capture food waste, I mean, every item you pull off the shelf for whatever reason is what we call salvaged or shrink. You take it out of the inventory. We know what's been taken out of the inventory, but we don't necessarily know what's been given away." 
stores also mentioned misperceptions and a lack of understanding and consistency around product dates (e.g., use-by, sell-by, best-by) caused them to pull perishable products close to their sell-by date even though they are often safe to eat. Once these products were culled or pulled for product dates, interviewees said that making it easy for employees to direct the food waste to the compost rather than the garbage was often challenging due their staff's competing work priorities; it also required the addition of staff training.

The most frequently cited barriers to food waste prevention and diversion of pre-consumer waste for restaurants and institutions were staff turnover, low staff motivation, and competing priorities for staff. Interviewees discussed the challenges of investing in ongoing employee training due to high turnover rates, and a few mentioned that these barriers were present even when tracking technologies and processes, such as LeanPath, were instituted. Restaurants and institutions also found the unpredictability of customer demand to be a challenge to preventing food waste or to estimating how much excess food would need to be diverted so that advance plans could be made.

Restaurants and institutions often felt that reducing portion sizes would only have a minimal effect on the compost stream and were unwilling to decrease portion sizes without accompanying patron demand because these portions are what their customers expect. This was depicted by an interviewee, "We would be very concerned if [food waste] as zero because then you'd feel like you're not feeding enough people." When asked if they would verbally cue customers to take their leftovers home in a to-go box, a few restaurants and institutions said they would not even though they provided such boxes on request; they cited food safety and container costs as reasons.

\section{Facilitators}

Grocery store interviewees reported that they have developed strategies to reduce the amount of food waste entering various diversion streams. First, with enhanced technologies they have tightened inventory management, improved food waste tracking to identify and diminish trouble spots, and developed creative in-house solutions to use food before it expires. For example, one interviewee talked about an in-house solution, "We have internal procedures that keep departments talking to each other; for example, if we have an excess of boneless chicken breast in the meat department and we're not going to sell through, we pull the chicken well before the sell-by date and transfer it to the deli and use it in the deli. It's that kind of monitoring internally that really keeps food waste at a low, low, level."

Similar to grocery stores, restaurants and institutions use tight inventory management and often have teams or programs that help them forecast their needs to reduce pre-consumer waste. They also provide employee-training programs that teach food-prepping techniques or use technologies, such as LeanPath, to help manage food waste. Several institutions and restaurants mentioned smaller, more frequent orders and/ or small batch cooking as a way to reduce food waste. O ne had created an employee bonus system to keep food waste in check.

For post-consumer waste, restaurants and institutions commonly used visual or verbal educational cues to help customers sort their food waste into the compost or be more cognizant about the amount of food they serve themselves. Two restaurants and institutions decreased the plates and/ or portion sizes to reduce postconsumer waste. Another hired employees to specifically sort food waste.

\section{F ood Recovery: C hallenges and Facilitators}

\section{Challenges}

All anti-hunger agencies emphasized the need for more donors and food donations, particularly healthy food such as produce and protein, to keep up with demand that has increased over the past few years. As one anti-hunger agency interviewee stated, "When the economy tanked, the crowd started growing... 2014 was the starkest of those years when we had a 32\% increase in demand." Half of the agencies reported that food donations have decreased over the past five years. Agencies stated that they have relationships with traditional donors, such as grocery stores and restaurants, and thus have begun to seek non-traditional donors 
(e.g., farmers, drug stores, schools) to increase their donation streams. Interviewees stated that, more recently, they are striving to make healthier foods available to their clients and, thus, have to compete with other anti-hunger agencies for healthier donations. One interviewee reflected on the increased demand for healthier food, "On a day when we're going to do 1,000-1,500 people, you can see the diabetes, you can see the obesity, and you can see the heart disease. I mean, you can see it just walking, the people who really need good food. We're really pushing nutrition as part of our mission." All but one anti-hunger agency reported that the most common food donations are produce, protein, bread, and shelf-stable products. D espite these regular donations, agencies report they still have to purchase between $5 \%$ and $40 \%$ of these types of food to fill nutritional gaps. O ne interviewee estimated that the additional purchase of these healthier food items cost them about US $\$ 140,000$ per year.

In addition to an inadequate supply of healthy food donations, the three main challenges that prevented anti-hunger agencies from obtaining more food were inadequate storage space, particularly for perishable items; the pick-up, delivery, and sorting of donations; and tension in the food distribution system between the efficiencies gained by systematizing the relationship between the donor and the anti-hunger agency and the need for more tailored donation relationships in order to meet client needs. Food storage, particularly for foods that require refrigeration, was an issue for almost every anti-hunger agency. As stated above, healthier food items, such as produce, protein, and dairy donations, are desired items. However, these items must be kept at the proper temperatures to maintain safety and quality, and several anti-hunger agencies lack adequate cold storage to meet demand. These storage issues made inventory management challenging for anti-hunger agencies. As one interviewee described,

I think that the second biggest challenge to space is the inventory management. It's our responsibility to make sure that every single person has an opportunity to receive our highest quality items. We can make educated guesses, but we don't know what the demand for an item will be, or what that demand for our service will be on any given day. It does happen on occasion where we get produce items that we limit, and then find out that we have more than enough. We could have given out all of it, and so then it sits in the warehouse, and it goes bad or something like that in a very short period of time. That happens on occasion as well and contributes to some of our waste.

The majority of anti-hunger agencies are not open during evening and weekend hours when the majority of food donations become available. Food donation pick-ups often require staff time and transportation, two resources that are typically in short supply for anti-hunger agencies who rely largely on volunteers with variable schedules. Because of this, anti-hunger agencies prefer donors that can deliver or that donate on a consistent schedule. If too many donations of nearly expired food arrive at once because of fluctuations in donations, there is limited staff and volunteer time to sort donations, or there is limited storage space, anti-hunger agencies report being unable to use them. These foods eventually have to be sorted and, once expired, retired to the compost. Antihunger agencies note that the associated compost fees can be expensive, often reaching a couple hundred dollars a month. As one interviewee described, "[D onors] want to donate the product when it's too late, and it's unusable and costing us a fortune in compost bills... I mean, if it's at that point, then they should toss it and they should pay their own garbage bill."

Finally, as large anti-hunger food distributors have entered the food recovery system to systematize the relationship between donors and antihunger agencies for efficiency gains, smaller antihunger agencies report lost relationships with important donors. While the smaller agencies affirmed that the large distributors do play beneficial roles by systemizing distribution and attracting new donors, they reported there were still tensions. These tensions included getting less of certain types of foods they were previously receiving, thus causing them to have to forge new donor 
relationships; receiving more food than they could use but being unable to redistribute it to other antihunger agencies because of contractual reasons; and having to sign contracts with large distributors that often require them to accept more unhealthy food than they would like as part of a "package" with healthy food. An interviewee explained how this worked:

[The food distributor] didn't always manage the grocery rescue program. Prior to that, it definitely was an individual agency and a relationship with a grocery store... then [food distributor] developed contract relationships with national grocery chains. [They] came in and said that okay, now you're going to sign the contract with us... and so the relationship was taken out of the hands of the food bank and the grocery store and went to [food distributor].

Another interviewee described the inability to forge relationships with donors of healthy food and to redistribute excess food,

... because they are this large organization it's a monopoly where organizations like [ours] can't go in and say that we'll come in and pick up after farmers market every Saturday and every Sunday, and then we'll redistribute that food to 26 other organizations on Monday. What we have to do is go and get that food and then try to use it within our organization. That continues to be the major hurdle... to come over to become the umbrella for the other organizations so that we can redistribute.

Businesses cited many challenges with food donation. For grocery stores, challenges included food safety concerns and unreliable donation pickups. In order to donate perishable items that are safe to eat, grocery stores must donate them prior to expiration, find on-site storage for the items until they are picked up, and in some cases deal with internal and/ or corporate business policies that regulate what can be donated. O ne grocery store described how they donate items to the food bank before they expire, "The primary push is going to be the expiration or sell-by dates. Take milk as an example--we pull it off the shelf three or four days before its sell-by date so that when it goes to the food banks, it's still got several days of life on it." Scheduling donation pick-ups with antihunger agencies can also be challenging since volunteer staffing often contributes to inconsistent scheduling. If pick-ups are missed or problems arise, employees at the stores must take time to work around this problem or these food donations have to be composted. One interviewee described this:

The challenges would be refrigerated product. You start to worry about health and safety when it comes to refrigerated product. You then have another spot where product is going to be stored for food banks. That would be one challenge. Another challenge would be that sometimes because food banks [are] often run with volunteers, sometimes they don't show up. And so then the product ends up being picked up at the end of the day and put into the compost.

For restaurants and institutions, the most frequently mentioned challenges to food donation included where to store items awaiting pick-up and unreliable or inconvenient pick-up schedules. O ther challenges noted were the time burden of training staff on how to donate food and a lack of resources addressing how to donate food. Since restaurants and institutions often have more inconsistent food donations, anti-hunger agency pickups are scheduled less frequently, or they are scheduled as soon as can be arranged once food is available. This makes food storage prior to pick-up a challenge. Due to restaurant and institution operating hours, they often needed to work with food banks that were flexible and could pick-up donations in a specific time window that was favorable to the business. O ne interviewee described,

Yes, I mean, the logistics is the tough part because we have to have someone who can pick up. We don't have facilities or the ability to load it all up, and to get it and transport it 
to them. It has to be food that's usable for that organization, and it has to be the right time window for them to be able to pick up and recover the food. I mean, we are operating a business and so we have business needs that supersede a lot of this stuff.

The time and training involved in the donation process was another challenge. For example, food banks often require prepared foods be put in specific pans or bags; this puts the burden of packaging on the businesses. Finally, a lack of resources about food donation for businesses was brought up as a barrier to donation. Notably, food safety did not come up as a challenge for restaurants and institutions, with all interviewees stating they were protected under the Good Samaritan Law or had established internal business policies that protected them (Bill Emerson Good Samaritan Food D onation Act, 42 U.S.C. § 1791).

Importantly, many food-generating businesses have recently begun to improve their food waste prevention strategies, and this has resulted in a reduction in food donations. O ne business interviewee reflected on this,

With people becoming more aware of overproducing and food waste, what is that next step going to be 3,4 , or 5 years from now? When there isn't a lot of donated product? How are these food banks going to get this? I think it's wonderful that we're all talking about it and that it's the right thing to do, but then we also need to think about okay, what is that going to look like five years from now?

\section{Facilitators}

Anti-hunger agencies gave examples of a number of facilitators they use to overcome food recovery system barriers, including forming farm-to-food bank relationships and implementing logistics improvement programs. More than half of the antihunger agencies received donations from farmers markets or local farms to increase the amount of healthy foods they can provide to their clients. To amplify this farm-to-food-bank relationship, one anti-hunger agency has partnered with a neighborhood farmers market to provide clients with monetary vouchers that can be used at a local farmers market. One anti-hunger agency embarked on logistics improvement to streamline standardized activities and processes, such as flow for clients and pick-ups, and to improve food inventory. The benefits of this program are described by the interviewee,

Over the course of the last year, we conducted dozens and dozens of experiments and made small changes here and there that eventually added up to pretty dramatically reducing our guest wait time by about $60 \%$, and [it] is allowing us to get 120-140 people through in an hour, whereas before we were lucky to get 50-60 through in an hour. We are able to do that without any reduction in quality or quantity of food that we were giving away.

Interviews with businesses produced a very different set of facilitators. The majority of businesses said the primary reason they donated food was to ensure it is being put to good use and to support their local community. As one business interviewee illustrated,

Yes, I think that on a pure capitalistic level, you know, we'd be paying more money in trash if we threw away our food. Really, it's like part of our mission... I think that it's part of a sustainable model to serve good food to the entire community... I'm really glad that we do it and I love taking credit for it, but at the end of the day it just makes sense. I like to think that I'm a good guy, but really it's just because it makes sense.

O nly one business mentioned receiving tax writeoffs as an incentive for food donation.

Several businesses discussed the need for a streamlined system that makes it easy for businesses to donate: "I think if there was a resource that was readily available that said, 'Here's how you do it and this is the pickup date,' and just something that answered commonly asked questions like 'can I donate frozen products?' We don't know. Do they have a freezer?" Moreover, because many businesses were not aware of the federal tax 
incentives for food donation, they felt that more businesses would be interested in donating if this were known. As one interviewee said,

Now, I think that there was talk of a tax code where you got like $150 \%$ of what you donated, the value of what you donated for food to alleviate hunger in these types of programs. If that were the case, I would imagine that rather than doing it sporadically and incidentally, more grocery stores would do it as a focus, because now they've got a huge incentive to do it.

Finally, businesses thought the idea of a central drop-off point to take donations might be attractive. As described by one interviewee, "I'd love to just have one place where you can just drop

Table 1. Summary of the Barriers and Facilitators of Food-Generating Businesses to Food Waste Prevention and Recovery

Food Waste Prevention

Barriers
Facilitators

\section{Grocery Stores}

- Customer expectations of food quality and abundance.

- Misconceptions about sell-by and/ or use-by dates.
- Tighter inventory management.

- Better communication and tracking across departments.

\section{Restaurants and Institutions}

- High staff turnover rates.

- Low staff motivation.

- Competing priorities for staff time and attention.

- Unpredictability of consumer purchases.

- Customer expectations regarding large portion sizes.
- Tighter inventory management and better forecasting systems, often via waste audits or technology.

- Offering high-quality employee trainings.

- Small-batch cooking or reducing portion sizes.

- Visual and/or verbal cues to customers about food portion sizes and/or proper composting.

Food Waste Recovery

Barriers

Facilitators

\section{Grocery Stores}

- Concerns about donating unsafe food (e.g., donating prior to product expiration, ability to store perishable items properly until picked up).

- Unpredictability of donation pick-ups.

- Improved food waste prevention resulting in fewer food donations.
- Mission and values of putting food to good use and supporting the community.

- Financial incentives.

Restaurants and Institutions

- Inadequate holding space for foods prior to pick-up.

- Unpredictability and inconvenience of donation pick-ups.

- Staff training needed to make donation happen.

- Lack of resources on how and where to donate food.

- Improved food waste prevention resulting in less food donations.
- Mission and values of putting food to good use and supporting the community.

- Financial incentives. 
everything off... Y ou just drop off all the food there and it just goes from there to wherever." See Table 1 for a summary of the challenges and facilitators to food waste prevention and recovery for food-generating businesses.

\section{Composting: Challenges and F acilitators}

\section{Challenges}

As noted above, anti-hunger agencies reported the cost burden of composting and expressed that funds spent on composting fees could be put to better use. One interviewee reflected, "Ultimately if we as food banks just become dumping grounds for compost, it really kind of prevents us from being better at what we're trying to do, which is to feed hungry families in our community."

Businesses reported that time, cost, and confusion were barriers associated with composting. Some businesses reported that consumers generated a large portion of their food waste. Interviewees noted that customers seem to be confused about what is compostable and surmised that this was due to a variety of factors: it is time-consuming to sort food waste and packaging, it is confusing given the level of detail needed to sort properly, and customers from diverse backgrounds and cultures may not be familiar with Seattle's requirements for sorting waste. Several of the interviewees that were part of national chains also described how the variability in composting policies across the U.S. contributes to the confusion and prevents chains from creating national employee training on the topic. O ne interviewee described, "We do have units that are segregated by trash, recycle, and compost. It is virtually impossible to monitor the public and make certain that they've truly separating their waste as they should."

\section{Facilitators}

Anti-hunger organizations did not mention any facilitators for composting but had ideas for public agency roles in this area, as described in the next section. Businesses used employee training to overcome composting barriers and visual or verbal cues to help consumers sort properly. A few interviewees reported using WISErg technology to overcome the cost barriers of composting. The WISErg is a bio-tech system (i.e., a tank-like system that is located on-site) that converts food waste into a nutrient-rich liquid that is refined into high-grade fertilizer that stores can sell back to consumers. O ne interviewee thought the WISErg technology should be explored to help anti-hunger agencies. That interviewee explained, "... if that solution is truly a better solution than just sending it to Cedar Grove compost, then maybe the financial resources to enable a handful of large food banks to be able to use that system would ultimately be better, right?"

L ocal G overnment and Public A gency Roles within the F ood Recovery System

Anti-hunger agencies had specific ideas for how local government and public agencies could support them to help address challenges in the system. These included outreach, policy approaches, grant funding, and drawing attention to the changing needs of the food-insecure. All anti-hunger agencies requested that the City help increase food donation via public outreach or policy approaches. Suggested strategies included implementing donor education about how and what to donate and Good Samaritan Laws; establishing stronger and better-defined regulations for the commercial sector to donate food; and utilizing City partnerships to create connections with non-traditional donors such as schools. Anti-hunger agencies also felt that grant funding from the City for infrastructure costs or negotiating reduced rates for some of the hidden costs of the system, such as compost bills and transportation fees (e.g., driver wages, fuel, and vehicle insurance), would allow them to put their focus on providing healthy food to clients. O ne interviewee suggested, "Reduced garbage and compost bills... I mean, it's thousands of dollars a month for garbage. So if they could work a deal to give a discounted rate or something to food banks and meal programs, that would be helpful." Finally, one anti-hunger agency felt that public agencies could help with future planning by tracking the changing demographics of food insecurity and helping to support disadvantaged populations as they move away from traditional geographic locations. The interviewee described this, saying, 
You have all of these disenfranchised populations that are being spread farther and farther out of the core that have no food resources. There is going to be a problem if they don't get the food resources...Everybody thinks that everybody who doesn't have anything to eat only lives in Pioneer Square. Y ou have a glut of food in Pioneer Square and no food in Georgetown, or no food in West Seattle and no food in Lake City.

The businesses interviewed had two common responses for how public agencies could help them prevent and divert wasted food. For food waste prevention, they suggested helping businesses learn how to measure their food waste through waste audits or technology. For food recovery, they suggested the creation of a donation resource that explained to businesses 'how' and 'what' to donate. They also recommended establishing a food diversion roundtable where Seattle businesses could come together and share best practices.

Two related recommendations emerged as cross-sector considerations. First, both sectors discussed the tension between food waste prevention and recovery efforts. That is, as food waste prevention efforts (i.e., the preferred action on the EPA's Food Recovery Hierarchy) succeed, there will be less wasted food to divert to the food recovery stream. Interviewees emphasized that public agencies should think ahead several decades from now on how they might help to feed foodinsecure people if local efforts to reduce food waste are successful. Second, both sectors thought that financial incentives for businesses to donate food might ensure a more consistent source of food donation, even as the volume of food waste hopefully decreases over time. Interviewees had suggestions to help achieve this, such as incentivizing businesses to donate a percentage of all their food well before expiration or creating a program that informs businesses of current anti-hunger sector needs and then incentivizes businesses to donate these particular in-demand foods. One interviewee described donor incentives,

Incentivizing donating food versus putting it in the waste stream... if you make that... beneficial enough to private businesses to do it. I guess that some of that is like education too. I imagine that there are probably a lot of small businesses that don't realize the benefits from a variety of ways: tax write-offs, utility savings potentially, the disposal fees and kind of all that stuff. There might be a lot of donors that don't realize the benefits of donating.

\section{Discussion}

Solving the multifaceted issues related to food waste prevention and diversion will be challenging. The UW CPHN worked closely with the City in analyzing the findings and developing a set of major recommendations that the City felt they could successfully implement. While these recommendations were developed for the City of Seattle, the first three recommendations could be beneficial for any local government ( $\mathrm{Otten}$ et al., 2016). First, a systems approach must be taken to identify crosssector problems and integrate solutions. This approach should incorporate equity goals or ways to enhance inclusion and equity for marginalized groups or communities. EPA's Food Recovery Hierarchy should be applied to approach and prioritize food waste problems and solutions. To date, most local governments do not have a centralized agency or position dedicated to food waste issues (Benson et al., 2017). Thus, a staff person or possibly an office should be dedicated to food waste to help coordinate and strengthen efforts and apply an equity lens. Similarly, without a centralized agency, position, or program, there is typically no dedicated funding for coordinating food waste reduction within the local government or addressing infrastructure problems that hinder the inclusion of marginalized groups. Local governments should consider exploring cross-department intersections to generate funding or staff collaboration. Another potential avenue for funds could be using composting-ordinance-generated fines to fund programs or education. Finally, local governments could help generate systems-oriented approaches by convening a wide variety of stakeholders through a venue, such as a roundtable or forum, to discuss comprehensive approaches and best practices. These types of forums might also 
help support the critical challenges that emerged from this study that are difficult for local governments to tackle but important for them to lead on and monitor. O ne example of such a challenge is the act of grappling with the increase and growth of food insecurity beyond local government service borders or the reduction in food donations experienced by anti-hunger agencies due to improvements in businesses's food waste prevention efforts. The inclusion of anti-hunger agency clients as stakeholders would also enhance equity for the marginalized communities that are identified in the EPA food recovery hierarchy. By tracking these challenges closely with stakeholders, local governments might be in a position to work across sectors to generate new and creative solutions.

Second, developing standardized and consistent metrics is essential for understanding and scaling work within and between sectors, for measuring progress toward goals or fluctuations in the system, and for identifying priorities. While standardized metrics are under development by several national entities, local governments could help to review and recommend which ones sectors should use (Food Loss \& Waste Protocol, 2017; High Level Panel of Experts [HLPE], 2014). In addition, local governments should support the collection of qualitative data to contextualize the quantitative data while the system is in still in its nascent stage.

Third, the emergency food system needs local government support to help it function optimally. Infrastructure costs, such as the costs of refrigerated trucks or storage and the costs of composting expired food, are barriers to food recovery. In addition, integration is needed within anti-hunger agencies and between sectors, such as tools and technologies to increase connectivity and help deliver particular types and quantities of food ondemand as well as a means for considering inclusivity and equitability in distributing recovered foods. Local governments should explore ways to fund infrastructure costs or reduce or waive composting fees. Local governments should also explore for pre-existing tools or technologies or partner with other organizations to develop tools and technologies to improve integration within and between system stakeholders, such as technology that tracks food bank inventory with $\mathrm{Q} R$ codes or an app that connects donors with anti-hunger agencies. In order to help support increased donations of nutritious foods, the City should evaluate the possibility for scaling up some of the innovative solutions discussed by interviewees, such as increasing the number and size of farms dedicated to serving food banks. For example, the South King County Food Coalition worked with King County government to convert a former golf course into a farm that provides fresh produce to food banks in south King County, Washington (Elk Run Farm, 2017).

Fourth, food waste assessments piloted by businesses in partnership with SPU indicate that there may be misconceptions between the amount and types of waste that businesses think they are generating and what is really generated. The City should pilot another phase of this work with both a larger number and a wider variety of commercial businesses to better understand the current state of wasted food. Local governments should also consider how to adapt food waste assessments for different types of businesses and to support businesses conducting food waste audits. O ne way to achieve this might be to collect best practices and highlight successes via case studies that can be shared.

Finally, business interviewees underscored that they act in response to perceptions about consumer desires, such as overstocking produce displays for visual effects, culling even lightly blemished produce, and serving large portions. This can result in food waste that may be unnecessary. Research on consumer attitudes and expectations is needed to understand which food waste prevention strategies can be successfully implemented.

L imitations

This study was limited by small sample size and geographic location and thus may not be generalizable to other anti-hunger agencies and foodgenerating businesses, especially outside of the geographic region. Some types of food-generating businesses were represented by only one business, and thus their responses may not be reflective of the type as a whole. Nearly half of the businesses contacted for this study did not respond to the 
study invitation; only businesses that were participating in food recovery responded, and thus selection bias may be present in the findings.

\section{Conclusion}

The first-ever U.S. food waste reduction goals were set in 2015 to reduce the serious economic, environmental, and social consequences of excess food loss and waste. Local governments are well positioned to support these goals through local-level innovations and by taking a system-and equityoriented approach in bringing together various sectors to reduce food prevention and recovery related issues. This study presents the key challenges and facilitators identified by anti-hunger agencies and food-generating businesses in addressing food waste prevention, recovery, and composting, and how they interrelate. Study findings also provide insights into how these sectors think local governments could best be involved. While local governments may be limited by funding or staffing constraints, they can use this information to develop creative cross-sector approaches that incorporate equity and inclusivity principles to solve food waste problems. Additional research is needed to better quantify the problems identified here, to hypothesize potential solutions, and to document, test, and compare the effectiveness of different approaches.

\section{Acknowledgments}

The authors would like to thank Liz Fikejs, Senior Conservation Program Manager with Seattle Public Utilities, and Sharon Lerman, City of Seattle Food Policy Advisor, for assisting with the development of interview guides and identifying agencies.

\section{References}

Benson, C., D aniell, W., \& Otten, J. J. (2017). A qualitative study of United States food waste programs and activities at the state and local level. Journal of $\mathrm{H}$ unger and E nvironmental $\mathrm{N}$ utrition. https:/ / doi.org/ 10.1080/ 19320248.2017.1403408

Bill Emerson G ood Samaritan Food D onation Act, 42 U.S.C. § 1791. Retrieved November 29, 2017, from https:/ / www.law.comell.edu/ uscode/ text/ 42/ 1791

Brinkmann, S. (2013). Q ualitative interviewing (Series in U nderstanding qualitative research). New Y ork: Oxford University Press.

Buzby, J. C., \& Hyman, J. (2012). Total and per capita value of food loss in the United States. Food Policy, 37(5), 561-570. https:// doi.org/ 10.1016/j.foodpol.2012.06.002

Buzby, J. C., Farah-Wells, H., \& Hyman, J. (2014). The estimated amount, value, and calories of postharvest food losses at the retail and consumer levels in the United States. United States D epartment of Agriculture (USD A)-Economic Research Service, E onomic Information Bulletin N 0. E IB-121. https:/ / doi.org/ 10.2139/ ssm.2501659

City of Seattle, Office of Sustainability and Environment. (2012). Seattle Food Action Plan. Retrieved November 29, 2017, from https:/ / www.seattle.gov/ environment/ food/ food-action-plan

City of Seattle. (2013). Seattle Climate Action Plan. Retrieved November 29, 2017, from http:/ / www.seattle.gov/ environment/ climate-change/ climate-action-plan

City of Seattle. (2015). Food waste requirements. Retrieved November 29, 2017, from http:// www.seattle.gov/ util/ MyServices/FoodY ard/ HouseResidents/ FoodWasteRequirements/ index.htm

Coleman-Jensen, A., Rabbitt, M. P., G regory, C. A., \& Singh, A. (2016). H ousehold food security in the U nited States (Economic Research Report No. 215). Retrieved from https:/ / www.ers.usda.gov/ publications/ pubdetails/ ?pubid $=79760$

Dedoose [Computer software]. (2016). Version 7.0.23. Los Angeles, California: SocioCultural Research Consultants, LLC.

Elk Run Farm (2017). About Elk Run Farm. Retrieved January 25, 2018, from https:/ / elkrunfarm.wordpress.com/ about-2/

Ernsdorff, S. (2009). Pilot project final report: C ommercial food waste reduction using L eanPath. Report commissioned by Seattle Public Utilities.

Food Loss \& Waste Protocol. (2017). Homepage. Retrieved November 29, 2017, from http:/ flwprotocol.org/ 
Guest, G., \& MacQ ueen, K. M. (Eds.) (2008). H andbook for team-based qualitative research. Plymouth, United Kingdom: Altamira Press.

Gunders, D. (2012). W asted: H ow A merica is losing up to 40 percent of its food from farm to fork to landfill (Issue Paper No. 12-06B). Retrieved from https:/ / www.nrdc.org/ sites/ default/ files/ wasted-food-IP.pdf

Hall, K. D ., Guo, J., D ore, M., \& Chow C. C. (2009). The progressive increase of food waste in America and its environmental impact. PloS 0 ne, 4(11), e7940. https:/ / doi.org/ 10.1371/ journal.pone.0007940

Hanson, C., \& Mitchell, P. (2017). The business case for reducing food loss and waste: A report on behalf of C hampions 12.3. Retrieved from https:// champions123.org/ the-business-case-for-reducing-food-loss-and-waste/

High Level Panel of Experts [HLPE]. (2014). Food losses and waste in the ontex $t$ of sustainable food systems: A report by the H igh L evel Panel of E x perts on food searity and nutrition. Retrieved from http:// www.fao.org/ 3/ a-i3901e.pdf

MacQueen, K. M., McLellan, E., Kay, K., \& Milstein, B. (1998). Codebook development for team-based qualitative analysis. Cultural A nthropology M ethods, 10(2), 31-36. https:/ / doi.org/ 10.1177/ 1525822X 980100020301

Miles, M. B., Huberman, A. M., \& Saldana, J. (2014). Q ualitative data analysis: A methods sourcebook (3rd ed.). Thousand Oaks, Califormia: SAGE.

Musick, M. (2010). Seattle Public U tilities F ood Recovery Program - 2010 final report. Report commissioned by Seattle Public Utilities.

National Resources D efense Council (NRD C). (2017). W asted: H ow A merica is losing up to 40 percent of its food from farm to fork to landfill (2nd ed.). Retrieved from https:/ / www.nrdc.org/ sites/ default/ files/ wasted-2017-report.pdf

Otten, J., D iedrich, S., G etts, K., \& Benson, C. (2016). F ood waste prevention and recovery assessment report. Retrieved from https:// depts.washington.edu/ uwcphn/ reports/ SeattleFoodWasteReport.PDF

Questad, T., \& Murphy, L. (2014). Household food and drink waste: A product focus. Retrieved from http:// www.wrap.org.uk/ sites/ files/ wrap/ Product-focused\%20report\%20v5 3.pdf

ReFED . (2016). A roadmap to reduce U .S. food waste by 20 percent. Retrieved from https:// www.refed.com/downloads/ ReFED Report 2016.pdf

Seattle Public Utilities Staff and Cascadia Consulting G roup, Inc. (2012). 2012 ommercial and self-haul waste streams composition study final report. Retrieved http:/ / www.seattle.gov/ util/cs/groups/ public/@ @ spu/ @ garbage/ documents/webcontent/ 01 026659.pdf

Seattle Public Utilities (SPU). (2014). A ssessment \& recommendations for the Seattle Public U tilities 2014 F ood Recovery Program. Report commissioned by Seattle Public Utilities.

State of Washington. (2018). House Bill 2411: Reducing wasted food in order to fight hunger and reduce environmental impacts. Retrieved January 25, 2018, from http:/ / app.leg.wa.gov/ billsummary?BillNumber=2411\&Y ear=2017

U.S. D epartment of Agriculture, Food and Nutrition Service (USD A). (2016). N utrition program fact sheet: The E mergency Food A ssistanœ Program. Retrieved November 29, 2017, from https:/ / fnsprod.azureedge.net/ sites/ default/ files/ tefap/ pfs-tefap.pdf

U.S. Environmental Protection Agency (U.S. EPA). (2015a). Sustainable management of food: Food Recovery Hierarchy. Retrieved November 29, 2017, from https:/ / www.epa.gov/ sustainable-management-food/ foodrecovery-hierarchy

U.S. Environmental Protection Agency (U.S. EPA). (2015b). Overview of greenhouse gases. Retrieved November 29, 2017, from http:// www3.epa.gov/ climatechange/ ghgemissions/ gases/ ch4.html

U.S. Environmental Protection Agency (U.S. EPA). (2015c). Sustainable management of food basics. Retrieved November 28, 2017, from http:// www2.epa.gov/ sustainable-management-food/ sustainable-management-foodbasics\#why 